\title{
Controle de plantas de soja e supressão do capim em milho consorciado com Brachiaria ruziziensis
}

\section{Soybean control and grass suppression in maize with Brachiaria ruziziensis intercropped}

\author{
José Fernando Jurca Grigolli *, Douglas de Castilho Gitti ${ }^{1}$, André Luis Faleiros Lourenção'

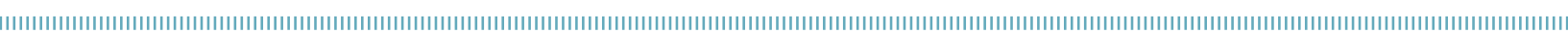

RESUMO: O objetivo deste trabalho foi avaliar a melhor dose de atrazina no controle de plantas de soja em meio ao milho safrinha consorciado com Brachiaria ruziziensis (B. ruziziensis), bem como sua interação com diferentes doses de nicosulfuron, de forma a não afetar os benefícios do consórcio. Foram realizados dois bioensaios, o primeiro com seis doses de atrazina $(0 ; 0,6 ; 0,8 ; 1,0 ; 1,2$; e $\left.1,4 \mathrm{~kg}_{\text {i.a. }} \mathrm{ha}^{-1}\right)$. As avaliaçóes foram realizadas 15 e 30 dias após a aplicaçáo (DAA), baseadas na porcentagem de controle das plantas de soja, no número de plantas de $B$. ruziziensis, no rendimento de grãos de milho e na massa seca do capim. $O$ segundo bioensaio foi conduzido em esquema fatorial 3 (doses de nicosulfuron) $\times 2$ (sem e com atrazina), com duas testemunhas adicionais (testemunha capinada e testemunha sem capina). As doses de nicosulfuron utilizadas foram 2,0; 4,0; e 6,0 $\mathrm{g}_{\text {i.a. }} \mathrm{ha}^{-1}$, e a dose de atrazina foi de $0,8 \mathrm{~kg}_{\text {i.a. }}$ ha $^{-1}$. Doses crescentes de atrazina resultaram em melhor controle das plantas de soja e maior rendimento de grãos de milho. Doses superiores a $1,0 \mathrm{~kg}_{\text {i.a. }}$ ha $^{-1}$ de atrazina resultaram em redução na massa seca do capim. A adição de $0,8 \mathrm{~kg}_{\mathrm{i} . \mathrm{a} .} \mathrm{ha}^{-1}$ de atrazina com 2,0; 4,0; ou 6,0 $\mathrm{g}_{\text {i.a. }}$ ha $^{-1}$ de nicosulfuron aumentou o controle de plantas de soja em comparaçáo com as doses isoladas de nicosulfuron, não influenciou o número de plantas e a massa seca do capim e proporcionou incremento no rendimento de grãos de milho.

PALAVRAS-CHAVE: Zea mays; herbicida; safrinha; consórcio.

\begin{abstract}
The aim of this study was to evaluate the best dose of atrazine in soybean control in winter maize intercropped with Brachiaria ruziziensis (B. ruziziensis), as well as its interaction with different doses of nicosulfuron, in a way as not to affect the benefits of farming-pasture integration. Two bioassays were made, the first one with six doses of atrazine $(0.0,0.6,0.8,1.0,1.2$, and $\left.1.4 \mathrm{~kg}_{\text {a.i. }} \mathrm{ha}^{-1}\right)$. Evaluations were performed 15 and 30 days after application, based on the percentage of soybean plants control, number of plants of $B$. ruziziensis, maize grain yield and dry mass of the grass. The second bioassay was conducted in split plot 3 (doses of nicosulfuron) $\times 2$ (with and without atrazine), with two additional witnesses (hand weeded and weeded treatment). Nicosulfuron doses used were 2.0, 4.0 and $6.0 \mathrm{~g}_{\text {a.i. }}$ ha $^{-1}$, and atrazine dose used was $0.8 \mathrm{~kg}_{\text {a.i. }} \mathrm{ha}^{-1}$. Increasing doses of atrazine resulted in better soybean plants control and higher maize grain yield. Doses higher than $1.0 \mathrm{~kg}_{\text {a.i. }} \mathrm{ha}^{-1}$ of atrazine resulted in decreased dry mass of the grass. The addition of $0.8 \mathrm{~kg}_{\text {a.i. }} \mathrm{ha}^{-1}$ of atrazine with 2.0, 4.0 and $6.0 \mathrm{~g}_{\text {a.i. }}$ ha $^{-1}$ of nicosulfuron increased soybean plants control compared with single doses of nicosulfuron, did not influence the number of plants nor dry mass of the grass and provided increase in maize grain yield.
\end{abstract}

KEYWORDS: Zea mays; herbicide; in-between season; intercrop. 


\section{INTRODUÇÃO}

A regiáo Centro-Oeste é a maior produtora de milho safrinha do Brasil, com uma área de aproximadamente 5,6 milhóes de hectares plantados em 2013 - um acréscimo de mais de 23\% em relação à safrinha de 2012 (CONAB, 2013).

A produção contínua de soja e milho safrinha pode não ser sustentável, principalmente por problemas com o manejo do solo relativos à baixa cobertura com palha e à redução do teor de matéria orgânica, que aumentam a suscetibilidade à erosão hídrica e às perdas de água por evaporação, resultando em maior compactação do solo (BEUTLER; CENTURION, 2004). Além disso, há o aumento da suscetibilidade da cultura aos períodos de estiagem, com redução no rendimento de grãos (FRANCHINI et al., 2008).

O consórcio do milho safrinha com espécies forrageiras tem sido uma prática bastante difundida dentro da integraçáo lavoura-pecuária (JAKELAITIS et al., 2004; FREITAS et al., 2005). A cultura do milho possui características favoráveis para o cultivo consorciado, como alto porte das plantas e altura de inserção das espigas, permitindo que a colheita ocorra sem interferência das plantas forrageiras (ALVARENGA et al., 2006).

Entretanto, esse sistema é complexo e deve levar em conta a forma de implantação da cultura, a disposição e a infestaçấo das plantas daninhas, bem como a cultura antecessora (JAKELAITIS et al., 2004). Brachiaria ruziziensis (B. ruziziensis) é a espécie de capim mais indicada para o sistema plantio direto, pelas características de rápido crescimento inicial, qualidade da forragem, boa cobertura de solo e facilidade de manejo para implantação da soja na subsequência (CECCON et al., 2013).

Em sistemas de produção consorciados, as espécies utilizadas estáo sujeitas à competiçâa entre si, além da concorrência naturalmente exercida pelas plantas daninhas, como plantas de soja que rebrotam e competem com o milho e com o capim. Um dos principais entraves na implantação do consórcio é o manejo tanto das espécies forrageiras quanto das plantas daninhas, uma vez que o cultivo leva em consideração a convivência de duas culturas distintas, porém, com comportamentos ecofisiológicos semelhantes, dificultando a seleção de tecnologias sem que haja prejuízos à cultura do milho pela mato-competição (DAN et al., 2012). Essa é uma das principais demandas de pesquisa na atualidade, principalmente em função do aparecimento de biótipos de plantas daninhas resistentes a herbicidas (VILELA et al., 2011).

Nesse cenário, é fundamental planejar corretamente o manejo de herbicidas na área, visando controlar as plantas daninhas e suprimir parcialmente a forrageira (JAKELAITIS et al., 2005b). Uma das formas de reduzir os efeitos da competiçáo entre o milho e a forrageira é o uso de herbicidas em subdoses, visando regular o crescimento da forrageira, garantindo sua supressão adequada, sem afetar perdas excessivas na produção de massa seca (DAN et al., 2011), como o uso de baixas doses de nicosulfuron para suprimir o desenvolvimento da forrageira.

Em função da carência de pesquisas no âmbito do controle de plantas daninhas e supressão da espécie forrageira em sistemas de milho safrinha consorciado com braquiárias, o objetivo deste trabalho foi avaliar a melhor dose do herbicida atrazina no controle de plantas de soja no milho safrinha consorciado com B. ruziziensis, bem como a interaçáo de atrazina com nicosulfuron no desenvolvimento do milho e de B. ruziziensis.

\section{MATERIAL E MÉTODOS}

O ensaio foi conduzido em área experimental da Fundaçấo MS, em Maracaju, Mato Grosso do Sul, Brasil, no período de fevereiro a julho de 2013. O híbrido de milho utilizado foi $\mathrm{P} 30 \mathrm{~F} 53 \mathrm{H}$ consorciado com B. ruziziensis. A população de milho utilizada foi de 57.000 sementes ha ${ }^{-1}$ e de $B$. ruziziensis foi de $1,7 \mathrm{~kg}$ de sementes viáveis ha ${ }^{-1}$. O espaçamento entre linhas adotado foi de $80 \mathrm{~cm}$.

A semeadura foi realizada com $B$. ruziziensis utilizando uma plantadeira com terceira caixa acoplada. A adubação foi realizada com $210 \mathrm{~kg} \mathrm{ha}^{-1}$ de 02-20-20 (N-P-K) na base e $166 \mathrm{~kg} \mathrm{ha}^{-1}$ de ureia em cobertura quando o milho estava com 3 folhas completamente expandidas, de acordo com a análise de solos.

\section{Bioensaio I: dose de atrazina no controle de plantas de soja}

$\mathrm{O}$ experimento foi conduzido em blocos casualizados, com seis doses de atrazina $\left(0,0 ; 0,6 ; 0,8 ; 1,0 ; 1,2 ;\right.$ e $\left.1,4 \mathrm{~kg}_{\text {i.a. }} \mathrm{ha}^{-1}\right)$ e cinco repetiçôes. Cada parcela foi constituída de 5 linhas com $12 \mathrm{~m}$ de comprimento $\left(48 \mathrm{~m}^{2}\right)$. A área útil da parcela foi considerada como as 3 linhas centrais de cada parcela, descontando-se $2 \mathrm{~m}$ de linha de cada extremidade $\left(19,2 \mathrm{~m}^{2}\right)$.

As aplicaçóes foram realizadas com pulverizador costal pressurizado com $\mathrm{CO}_{2}$, com pressáo constante de $276 \mathrm{kPa}$, equipado com barra de 3,0 m de largura efetiva e 6 pontas de pulverizaçáo do tipo leque duplo TJ 06110.02 , distanciadas em $0,5 \mathrm{~m}$, com volume de pulverizaçấo equivalente a $160 \mathrm{~L} \mathrm{ha}^{-1}$. As condições meteorológicas no momento da aplicação foram temperatura de $24,9^{\circ} \mathrm{C}, 90 \%$ de umidade relativa do ar e vento com $0,1 \mathrm{~m} \mathrm{~s}^{-1}$. No momento da aplicação constatou-se estádio fenológico V1 para o milho e B. ruziziensis iniciando a emergência.

As avaliaçóes de controle de plantas de soja foram realizadas pela comparaçáo visual com a testemunha por meio do conjunto da população das plantas de soja infestantes presentes nas parcelas aos 15 e 30 dias após a aplicação (DAA) dos tratamentos. Foi utilizada uma escala percentual, em que $0 \%$ 
representa ausência de sintomas de fitotoxicidade e 100\%, a morte das plantas (ASOCIACIÓN LATINOAMERICANA DE MALEZAS, 1974). Para a cultura do milho, foi avaliado também o rendimento de grãos do milho, por meio da colheita da área útil das parcelas.

Para a seletividade dos tratamentos com $B$. ruziziensis, utilizou-se um quadrado metálico de $0,8 \times 0,8 \mathrm{~m}$, lançado em dois pontos ao acaso por parcela aos 15 e 30 DAA. Em cada ponto, foi realizada a contagem do número de plantas de B. ruziziensis. A média de cada parcela foi constituída pela média dos dois pontos amostrados. Além dessa avaliação, foi realizada a medição da biomassa seca total da população de B. ruziziensis pela coleta das plantas presentes em dois pontos por parcela, na época de colheita da cultura, com o auxílio de um quadrado de ferro de $0,8 \times 0,8 \mathrm{~m}$. As amostras foram secas e pesadas com o auxílio de uma balança de precisão.

Os dados obtidos foram submetidos à análise de regressão na análise de variância $(\mathrm{p}<0,05)$.

\section{Bioensaio II: interação de atrazina e nicosulfuron no controle de plantas de soja e seus efeitos em milho e $B$. ruziziensis}

O experimento foi conduzido em blocos casualizados em esquema fatorial 3 (doses de nicosulfuron) $\times 2$ (sem e com atrazina), com duas testemunhas adicionais (testemunha capinada e testemunha sem capina) e cinco repetiçóes. As doses de nicosulfuron utilizadas foram 2,0; 4,0; e 6,0 $\mathrm{g}_{\mathrm{i} . \mathrm{a}} \mathrm{ha}^{-1}$, e a dose de atrazina, de $0,8 \mathrm{~kg}_{\text {i.a. }} \mathrm{ha}^{-1}$, de acordo com os resultados do Bioensaio I. Cada parcela foi constituída de 5 linhas com $12 \mathrm{~m}$ de comprimento $\left(48 \mathrm{~m}^{2}\right)$. A área útil da parcela foi considerada como as 3 linhas centrais de cada parcela, descontando-se $2 \mathrm{~m}$ de linha de cada extremidade $\left(19,2 \mathrm{~m}^{2}\right)$.

As aplicações foram realizadas com pulverizador costal pressurizado com $\mathrm{CO}_{2}$, com pressão constante de $276 \mathrm{kPa}$, equipado com barra de 3,0 m de largura efetiva e 6 pontas de pulverização do tipo leque duplo TJ 06 110.02, distanciadas em $0,5 \mathrm{~m}$, com volume de pulverização equivalente a $160 \mathrm{~L} \mathrm{ha}^{-1}$. As condiçôes meteorológicas no momento da aplicação foram temperatura de $24,6^{\circ} \mathrm{C}, 87 \%$ de umidade relativa do ar e vento com $0,1 \mathrm{~m} \mathrm{~s}^{-1}$. No momento da aplicaçáo constatou-se estádio fenológico V3 para o milho e $B$. ruziziensis em início de perfilhamento.

As avaliaçôes de controle de plantas de soja foram realizadas pela comparaçáo visual com a testemunha aos $30 \mathrm{DAA}$ dos tratamentos. Foi utilizada uma escala percentual, em que $0 \%$ representa ausência de sintomas de fitotoxicidade e $100 \%$, a morte das plantas (ASOCIACIÓN LATINOAMERICANA DE MALEZAS, 1974). Para a cultura do milho, foi avaliado também o rendimento de grãos do milho, por meio da colheita da área útil das parcelas.
Para a seletividade dos tratamentos a $B$. ruziziensis, utilizou-se um quadrado metálico de $0,8 \times 0,8 \mathrm{~m}$, lançado em 2 pontos ao acaso por parcela aos 30 DAA. Em cada ponto, foi realizada a contagem do número de plantas de $B$. ruziziensis. A média de cada parcela foi constituída pela média dos dois pontos amostrados. Além dessa avaliaçáo, foi realizada a medição da biomassa seca total da população de $B$. ruziziensis pela coleta das plantas presentes em dois pontos por parcela, na época de colheita da cultura, com o auxílio de um quadrado de ferro de $0,8 \times 0,8 \mathrm{~m}$. As amostras foram secas e pesadas com o auxílio de uma balança de precisão.

Os dados obtidos foram submetidos à análise de variância e as médias dos tratamentos, comparadas pelo teste de Tukey $(\mathrm{p}<0,05)$.

\section{RESULTADOS E DISCUSSÃO}

\section{Bioensaio I: dose de atrazina no controle de plantas de soja}

Os resultados obtidos quanto à porcentagem de controle de plantas de soja aos 15 e 30 DAA indicaram que houve significância na análise de regressão, de modo que a porcentagem de controle de plantas de soja respondeu de forma linear significativa e positiva nas duas avaliaçốes. Com o aumento da dose do herbicida, a porcentagem de controle aumentou de forma significativa. Doses superiores a $0,8 \mathrm{~kg}_{\text {i... }} \mathrm{ha}^{-1}$ atingiram porcentagem de controle aos 30 DAA superiores a $80 \%$, demonstrando que essas quantidades são as mais indicadas para o controle das plantas de soja infestantes na área (Fig. 1).

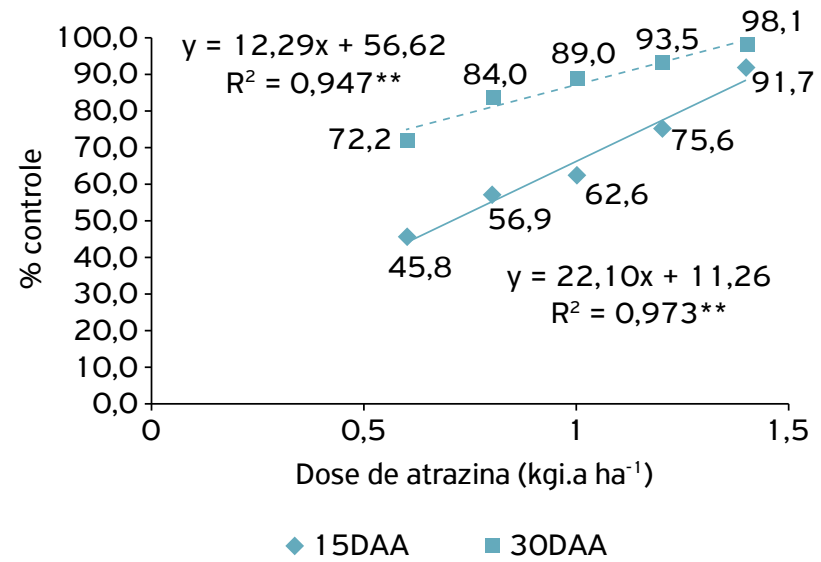

**significativo a $1 \%$ de probabilidade pela análise de regressão na análise de variância; DAA: dias após a aplicação.

Figura 1. Controle percentual de plantas de soja aos 15 e 30 dias após a aplicação de diferentes doses de atrazina na cultura do milho safrinha consorciado com Brachiaria ruziziensis. Maracaju, Mato Grosso do Sul, 2013. 
Também foi observado que as maiores doses aceleraram a velocidade de dessecação das plantas de soja, atingindo valores superiores a $90 \%$ na dose de $1,4 \mathrm{~kg}_{\text {i.a. }}$ ha $^{-1} 15$ DAA. Aos $30 \mathrm{DAA}$, as doses 0,8 e 1,0 $\mathrm{kg}_{\text {i.a. }}$ ha $^{-1}$ atingiram valores superiores a $80 \%$ de controle, enquanto doses de 1,2 e 1,4 $\mathrm{kg}_{\text {i.a. }} \mathrm{ha}^{-1}$ atingiram valores superiores a $90 \%$ de controle de plantas de soja (Fig. 1).

As doses de atrazina utilizadas não prejudicaram o desenvolvimento de plantas de B. ruziziensis, de modo que aos 15 e 30 DAA doses maiores do referido herbicida proporcionaram maior número de plantas de braquiária (Fig. 2). O comportamento do número de plantas de capim aos $15 \mathrm{DAA}$ apresentou-se linear, de modo que maiores doses proporcionaram melhor desenvolvimento do capim. Aos 30 DAA, o comportamento observado foi quadrático, de modo que doses superiores a $0,8 \mathrm{~kg}_{\text {i.a. }} \mathrm{ha}^{-1}$ não proporcionaram incrementos na quantidade de plantas de B. ruziziensis (Fig. 2).

O aumento do número de plantas de capim observado pode ter ocorrido em função do melhor controle das plantas de soja, o que possibilitou o melhor estabelecimento do capim no sistema de consorciação. Esse resultado indica que doses elevadas de atrazina podem resultar em prejuízos para o sistema milho consorciado com B. ruziziensis, mas que a falta de controle de plantas de soja também pode ser prejudicial, pois reduz o número de plantas de B. ruziziensis.

Apesar da não interferência no número de plantas de B. ruziziensis observadas com elevadas doses de atrazina, observou-se que doses elevadas do herbicida resultaram em redução na massa seca de $B$. ruziziensis, de modo que doses superiores a $1,0 \mathrm{~kg}_{\text {i.a. }} \mathrm{ha}^{-1}$ promoveram redução da massa seca produzida (Fig. 3). Esse resultado sugere que doses superiores a $1,0 \mathrm{~kg}_{\text {i.a. }}$ ha $^{-1}$ não devem ser utilizadas em cultivos de milho consorciado com B. ruziziensis, pois podem reduzir de forma significativa a palhada produzida pelo capim no final do ciclo de desenvolvimento do milho.

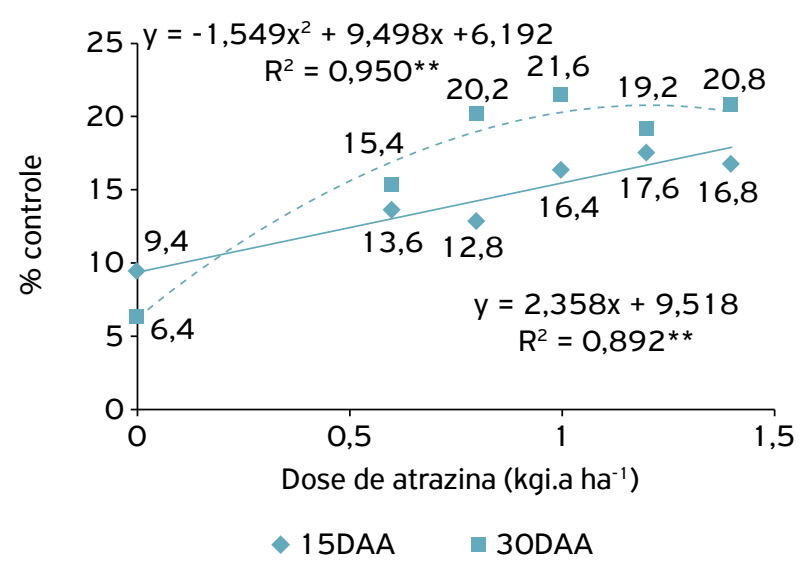

** significativo a $1 \%$ de probabilidade pela análise de regressão na análise de variância; DAA: dias após a aplicação.

Figura 2. Número de plantas de Brachiaria ruziziensis aos 15 e 30 dias após a aplicação de diferentes doses de atrazina na cultura do milho safrinha consorciado com Brachiaria ruziziensis. Maracaju, Mato Grosso do Sul, 2013.
A produtividade do milho indicou apresentar um padrão linear e crescente com as doses de atrazina utilizadas. Assim, doses maiores do herbicida proporcionaram incrementos no rendimento de grãos de milho (Fig. 4). Esse resultado foi obtido provavelmente em função da ausência de fitointoxicação das plantas de milho pelas doses de atrazina utilizadas, pelo controle das plantas de soja na área e pela supressáo do capim, o que proporcionou melhores condiçóes para o estabelecimento do milho.

Os resultados obtidos no Bioensaio I sugerem que altas doses de atrazina podem comprometer o cultivo do milho safrinha consorciado com B. ruziziensis. Observou-se incremento significativo na produtividade de milho com doses elevadas de atrazina, mas a produção de massa seca de capim foi comprometida, o que pode prejudicar o sistema de consorciação de cultivos. A redução da massa seca produzida pelo capim pode aumentar a suscetibilidade da cultura subsequente a
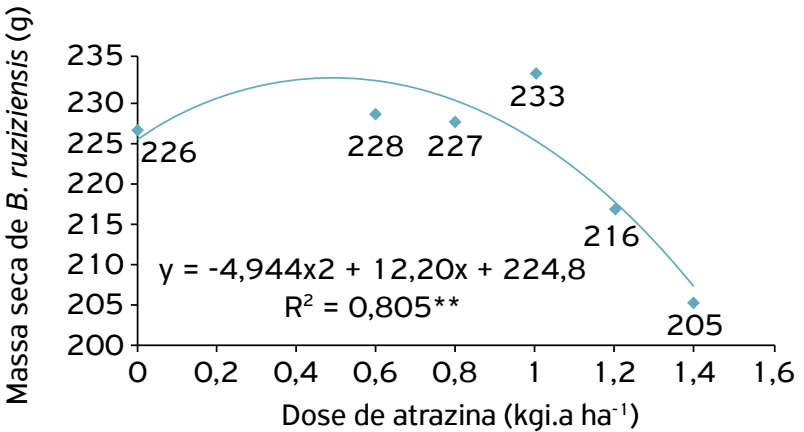

* *significativo a $1 \%$ de probabilidade pela análise de regressão na análise de variância.

Figura 3. Massa seca (g) de Brachiaria ruziziensis após a aplicação de diferentes doses de atrazina na cultura do milho safrinha consorciado com Brachiaria ruziziensis. Maracaju, Mato Grosso do Sul, 2013.

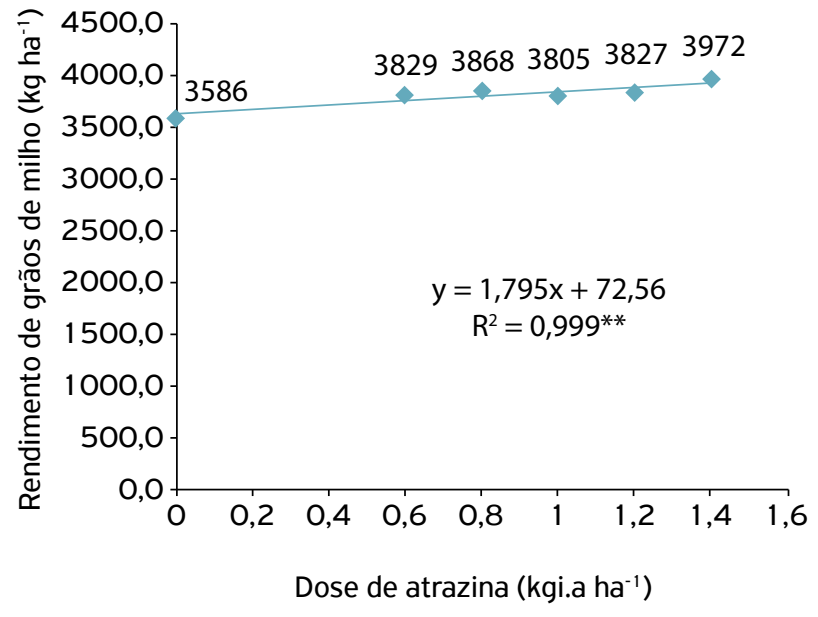

** significativo a $1 \%$ de probabilidade pela análise de regressão na análise de variância.

Figura 4. Rendimento ( $\mathrm{kg} \mathrm{ha-1)}$ de grãos de milho safrinha consorciado com Brachiaria ruziziensis tratados com diferentes doses de atrazina. Maracaju, Mato Grosso do Sul, 2013. 
períodos de estiagem, inclusive com redução na produtividade (FRANCHINI et al., 2008), fato comum em alguns estados do Brasil, como em Mato Grosso do Sul.

\section{Bioensaio II: interação de atrazina e nicosulfuron no controle de plantas de soja e seus efeitos em milho e $B$. ruziziensis}

Os resultados obtidos de porcentagem de controle de plantas de soja 30 DAA indicaram que todas as doses de nicosulfuron com a adiçấo de atrazina controlaram $100 \%$ das plantas de soja na área experimental, enquanto nos casos sem a adição de atrazina o controle ficou aquém do necessário, com valores de 29,21 e $28 \%$ para as doses de 2,4 e $6 \mathrm{~g}_{\text {i.a. }}$ ha $^{-1}$, respectivamente (Tabela 1).

Com relação ao número de plantas do capim B. ruziziensis, observou-se que as doses de nicosulfuron utilizadas sem e com a adição de atrazina não afetaram de forma significativa o número de plantas. Todos os tratamentos apresentaram estatisticamente os mesmos valores, inclusive entre as testemunhas com e sem capina (Tabela 2).

Quanto à massa seca do capim B. ruziziensis, observou-se que as doses de nicosulfuron utilizadas e a adição de atrazina náo reduziram de forma significativa a massa seca final das plantas de capim no momento da colheita do milho.

Tabela 1. Controle percentual de plantas de soja 30 dias após a aplicação de atrazina com diferentes doses de nicosulfuron na cultura do milho safrinha consorciado com Brachiaria ruziziensis. Maracaju, Mato Grosso do Sul, 2013.

\begin{tabular}{|c|c|c|c|}
\hline \multirow{2}{*}{ Nicosulfuron } & \multicolumn{2}{|c|}{ Atrazina } & \multirow{2}{*}{ Média } \\
\hline & Sem & Com & \\
\hline $2 \mathrm{~g}_{\text {i.a. }} \mathrm{ha}^{-1}$ & $29 \mathrm{aB}$ & $100 \mathrm{aA}$ & 64 a \\
\hline $4 \mathrm{~g}_{\text {i.a. }} \mathrm{ha}^{-1}$ & $21 \mathrm{aB}$ & $100 \mathrm{aA}$ & $60 \mathrm{a}$ \\
\hline $6 \mathrm{~g}_{\text {i.a. }} \mathrm{ha}^{-1}$ & $28 \mathrm{aB}$ & $100 \mathrm{aA}$ & $65 a$ \\
\hline Média & $26 \mathrm{~B}$ & $100 \mathrm{~A}$ & \\
\hline \multicolumn{3}{|c|}{ Testemunha capinada } & $100 \mathrm{a}$ \\
\hline \multicolumn{3}{|c|}{ Testemunha sem capina } & $\mathrm{Ob}$ \\
\hline \multicolumn{4}{|c|}{$F($ nicosulfuron $)=0,4543^{n s}$} \\
\hline \multicolumn{4}{|c|}{$\mathrm{F}($ atrazina $)=378,0783^{* *}$} \\
\hline \multicolumn{4}{|c|}{$F($ nicosulfuron*atrazina $)=5,4543^{* *}$} \\
\hline \multicolumn{4}{|c|}{$\mathrm{F}$ (herbicidas ${ }^{*}$ testemunhas $)=11,7134^{* *}$} \\
\hline \multicolumn{4}{|c|}{$\begin{array}{l}F \text { (testemunha capinada*testemunha sem capina) }= \\
230,3739^{* *}\end{array}$} \\
\hline$C V(\%)=17,4$ & & & \\
\hline
\end{tabular}

Médias sequidas pela mesma letra maiúscula na linha e minúscula na coluna não diferem estatisticamente entre si pelo teste de Tukey a $5 \%$ de probabilidade.

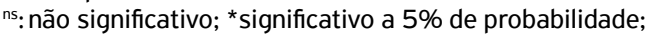

**significativo a $1 \%$ de probabilidade; CV: coeficiente de variação (\%).
Entretanto, é possível observar que a ausência de controle das plantas de soja (testemunha sem capina) acarretou no menor valor de massa seca de B. ruziziensis (Tabela 3).

Tabela 2. Número de plantas de Brachiaria ruziziensis 30 dias após a aplicação de atrazina com diferentes doses de nicosulfuron na cultura do milho safrinha consorciado com Brachiaria ruziziensis. Maracaju, Mato Grosso do Sul, 2013.

\begin{tabular}{|c|c|c|c|}
\hline \multirow{2}{*}{ Nicosulfuron } & \multicolumn{2}{|c|}{ Atrazina } & \multirow{2}{*}{ Média } \\
\hline & Sem & Com & \\
\hline $2 \mathrm{~g}_{\text {i.a. }} \mathrm{ha}^{-1}$ & 10,4 aA & 8,6 aA & $9,5 \mathrm{a}$ \\
\hline $4 \mathrm{~g}_{\text {i.a. }} \mathrm{ha}^{-1}$ & $7,4 \mathrm{aA}$ & $7,0 \mathrm{aA}$ & $7,2 \mathrm{a}$ \\
\hline $6 \mathrm{~g}_{\text {i.a. }} \mathrm{ha}^{-1}$ & $7,2 \mathrm{aA}$ & $10,6 \mathrm{aA}$ & $8,9 a$ \\
\hline Média & $8,3 \mathrm{~A}$ & $8,7 \mathrm{~A}$ & \\
\hline \multicolumn{3}{|c|}{ Testemunha capinada } & $11,6 a$ \\
\hline \multicolumn{3}{|c|}{ Testemunha sem capina } & $8,8 \mathrm{a}$ \\
\hline \multicolumn{4}{|c|}{$F($ nicosulfuron $)=1,6122^{\text {ns }}$} \\
\hline \multicolumn{4}{|c|}{$F($ atrazina $)=0,1359^{\text {ns }}$} \\
\hline \multicolumn{4}{|c|}{$F($ nicosulfuron*atrazina $)=2,0502^{\text {ns }}$} \\
\hline \multicolumn{4}{|c|}{$\mathrm{F}$ (herbicidas* testemunhas) $=2,3598^{\text {ns }}$} \\
\hline \multicolumn{4}{|c|}{$\mathrm{F}$ (testemunha capinada*testemunha sem capina) $=2,2201^{\mathrm{ns}}$} \\
\hline$C V(\%)=33,2$ & & & \\
\hline
\end{tabular}

Médias seguidas pela mesma letra maiúscula na linha e minúscula na coluna não diferem estatisticamente entre si pelo teste de Tukey a $5 \%$ de probabilidade.

ns: não significativo; *significativo a $5 \%$ de probabilidade;

**significativo a $1 \%$ de probabilidade; CV: coeficiente de variação (\%).

Tabela 3. Massa seca ( $\mathrm{g}$ ) de Brachiaria ruziziensis após a aplicação de atrazina com diferentes doses de nicosulfuron na cultura do milho safrinha consorciado com Brachiaria ruziziensis. Maracaju, Mato Grosso do Sul, 2013.

\begin{tabular}{|c|c|c|c|}
\hline \multirow{2}{*}{ Nicosulfuron } & \multicolumn{2}{|c|}{ Atrazina } & \multirow{2}{*}{ Média } \\
\hline & Sem & Com & \\
\hline $2 g_{\text {i.a. }} h^{-1}$ & 273,0 aA & 237,0 aA & 255,0 a \\
\hline $4 g_{\text {i.a. }} h^{-1}$ & 226,0 aA & 207,0 aA & $216,5 a$ \\
\hline $6 \mathrm{~g}_{\text {i.a. }} \mathrm{ha}^{-1}$ & 274,0 aA & 222,0 aA & 248,0 a \\
\hline Média & $257,7 \mathrm{~A}$ & $222,0 \mathrm{~A}$ & \\
\hline \multicolumn{3}{|c|}{ Testemunha capinada } & $288,0 \mathrm{a}$ \\
\hline \multicolumn{3}{|c|}{ Testemunha sem capina } & $219,0 \mathrm{~b}$ \\
\hline \multicolumn{4}{|c|}{$F($ nicosulfuron $)=1,7056^{\text {ns }}$} \\
\hline \multicolumn{4}{|c|}{$F($ atrazina $)=3,8692^{\text {ns }}$} \\
\hline \multicolumn{4}{|c|}{$\mathrm{F}$ (nicosulfuron*atrazina) $=0,2761^{\mathrm{ns}}$} \\
\hline \multicolumn{4}{|c|}{$\mathrm{F}$ (herbicidas*testemunhas) $=7,5028^{*}$} \\
\hline \multicolumn{4}{|c|}{ F (testemunha capinada*testemunha sem capina) $=4,7091$ * } \\
\hline $\mathrm{CV}(\%)=19,6$ & & & \\
\hline
\end{tabular}

Médias sequidas pela mesma letra maiúscula na linha e minúscula na coluna não diferem estatisticamente entre si pelo teste de Tukey a $5 \%$ de probabilidade.

ns: não significativo; *significativo a $5 \%$ de probabilidade;

** significativo a $1 \%$ de probabilidade; CV: coeficiente de variação (\%). 
Em trabalhos semelhantes conduzidos por FREITAS et al. (2005), os autores observaram a interferência de nicosulfuron, na dose de $4 \mathrm{~g}_{\text {i.a. }} \mathrm{ha}^{-1}$, na produção da biomassa de Urochloa brizantha (U. brizantha), fato não observado para a espécie avaliada no presente trabalho. JAKELAITIS et al. (2005a) também constataram que o nicosulfuron a partir de $4,0 \mathrm{~g}_{\text {i.a. }}$ ha $^{-1}$ na associação com $1,5 \mathrm{~kg}_{\text {i.a. }} \mathrm{ha}^{-1}$ de atrazina reduziu a biomassa produzida por $U$. brizantha. Dessa forma, pode-se observar que a dose de atrazina de $1,5 \mathrm{~kg}_{\text {i.a. }} \mathrm{ha}^{-1}$ pode estar associada a reduçóes na produção da biomassa de ambas as espécies de capim ( $U$. brizantha e B. ruziziensis), fato observado no presente trabalho para a espécie B. ruziziensis (Fig. 3).

Com relação ao rendimento de grãos de milho, os tratamentos com a adição de atrazina apresentaram incrementos significativos em todas as doses de nicosulfuron avaliadas (Tabela 4). Os resultados obtidos de rendimento de grãos de milho e massa seca de B. ruziziensis corroboram JAKELAITIS et al. (2005b), que verificaram que o uso do herbicida nicosulfuron

Tabela 4. Rendimento de grãos $\left(\mathrm{kg} \mathrm{ha}^{-1}\right)$ de milho safrinha após a aplicação de atrazina com diferentes doses de nicosulfuron na cultura do milho safrinha consorciado com Brachiaria ruziziensis. Maracaju, Mato Grosso do Sul, 2013.

\begin{tabular}{|c|c|c|c|}
\hline \multirow{2}{*}{ Nicosulfuron } & \multicolumn{2}{|c|}{ Atrazina } & \multirow{2}{*}{ Média } \\
\hline & Sem & Com & \\
\hline $2 \mathrm{~g}_{\text {i.a. }} \mathrm{ha}^{-1}$ & $3.025 \mathrm{aB}$ & $4.135 \mathrm{aA}$ & $3.580 \mathrm{a}$ \\
\hline $4 g_{\text {i.a. }} h^{-1}$ & $2.610 \mathrm{aB}$ & $4.125 \mathrm{aA}$ & $3.365 \mathrm{a}$ \\
\hline $6 \mathrm{~g}_{\text {i.a. }} \mathrm{ha}^{-1}$ & $2.835 \mathrm{aB}$ & $4.040 \mathrm{aA}$ & $4.128 \mathrm{a}$ \\
\hline Média & $2.825 \mathrm{~B}$ & $4.100 \mathrm{~A}$ & \\
\hline \multicolumn{3}{|c|}{ Testemunha capinada } & $4.045 \mathrm{a}$ \\
\hline \multicolumn{3}{|c|}{ Testemunha sem capina } & $2.085 b$ \\
\hline \multicolumn{4}{|c|}{$F($ nicosulfuron $)=4,6073^{* *}$} \\
\hline \multicolumn{4}{|c|}{$F($ atrazina $)=170,7929^{* *}$} \\
\hline \multicolumn{4}{|c|}{$F($ nicosulfuron*atrazina $)=4,6073^{* *}$} \\
\hline \multicolumn{4}{|c|}{$\mathrm{F}($ herbicidas $*$ testemunhas $)=16,4011^{*}$} \\
\hline \multicolumn{4}{|c|}{$\begin{array}{l}\text { F (testemunha capinada*testemunha sem capina) }= \\
134,3871^{* *}\end{array}$} \\
\hline $\mathrm{CV}(\%)=7,96$ & & & \\
\hline
\end{tabular}

Médias seguidas pela mesma letra maiúscula na linha e minúscula na coluna não diferem estatisticamente entre si pelo teste de Tukey a $5 \%$ de probabilidade.

ns: não significativo; *significativo a $5 \%$ de probabilidade;

** significativo a $1 \%$ de probabilidade; CV: coeficiente de variação (\%). em mistura com atrazina foi essencial no manejo satisfatório de plantas de soja no sistema milho consorciado com Brachiaria brizantha. Além disso, verificaram que a aplicação isolada de nicosulfuron e sua associação com atrazina causou injúrias de, no máximo, 1,7\%, o que comprova a seletividade desse tratamento na cultura do milho (KARAM et al., 2009).

A associação de nicosulfuron nas doses de 2,0; 4,0; e 6,0 $\mathrm{g}_{\text {i.a. }} \mathrm{ha}^{-1} \mathrm{com}$ atrazina na dose de $0,8 \mathrm{~kg}_{\text {i.a. }} \mathrm{ha}^{-1}$ pode ser adotada em sistemas de produção de milho safrinha em consórcio com a braquiária para o controle de plantas de soja no início do desenvolvimento da cultura sem comprometer a produção do capim no sistema plantio direto e o rendimento de grãos de milho.

De acordo com os resultados obtidos, observou-se que a utilizaçáo de doses crescentes de atrazina resultou em melhor controle das plantas de soja, não afetou o número de plantas de $B$. ruziziensis e promoveu maior rendimento de grãos de milho. Entretanto, doses superiores a $1,0 \mathrm{~kg}_{\text {i.a. }} \mathrm{ha}^{-1}$ de atrazina resultaram em redução na massa seca de B. ruziziensis, indicando que doses superiores a essa não devem ser utilizadas em sistemas de milho consorciado com B. ruziziensis.

A adição de $0,8 \mathrm{~kg}_{\text {i.a. }} \mathrm{ha}^{-1}$ de atrazina com 2,0; 4,0; ou $6,0 \mathrm{~g}_{\text {i.a. }} \mathrm{ha}^{-1}$ de nicosulfuron aumentou o controle de plantas de soja no sistema de cultivo do milho safrinha consorciado com B. ruziziensis, em comparação com as doses isoladas de nicosulfuron; não influenciou o número de plantas e a massa seca de B. ruziziensis; e proporcionou incremento no rendimento de grãos de milho, indicando que essa mistura de herbicidas pode ser utilizada no sistema de produção milho safrinha consorciado com B. ruziziensis sem afetar os benefícios do consórcio.

\section{CONCLUSÕES}

Doses crescentes de atrazina proporcionam melhor controle de tigueras de soja, melhor desenvolvimento do capim braquiária e maior produtividade do milho.

Doses superiores a $1,0 \mathrm{~kg}_{\text {i.a. }} \mathrm{ha}^{-1}$ de atrazina reduzem a massa seca de B. ruziziensis.

A mistura de nicosulfuron e atrazina aumenta o controle de plantas de soja, não interfere no desenvolvimento de B. ruziziensis e resulta em maior rendimento de grãos de milho.

| | | | | | | | | | | | | | | | | | | | | | | | | | | | | | | | | | | | | | | | | | | | | | | | | | | | | | | | | | | | | | | | | | | | | | | | | | | | | | | | | | | | | | | | | | | | | | | | | | | | | | | | | | | | | | | | | | | | | | | | | | | | | | | | | | | | | | | | | | | | | | | | | | | | | | | | | | | | | | | | | | | | | | | | | | | | | | | | | | | | | | | | | | | | | | | | | | | | | | | | | || || REFERÊNCIAS

ALVARENGA, R.C.; COBUCCI, T.; KLUTHCOUSKI, J.; WRUCK, F.J.; CRUZ, J. C.; GONTIJONETO, M.M.A cultura domilhona integração lavoura-pecuária. Sete Lagoas: Embrapa Milho e Sorgo, 2006. (Circular técnica, 80).
ASOCIACIÓN LATINOAMERICANA DEMALEZAS. Recomendaciones sobre unificación de los sistemas de evaluación en ensayos de control de malezas. Alam, v.1, p.35-38, 1974. 
BEUTLER, A.N.; CENTURION, J.F. Compactação do solo no desenvolvimento radicular e na produtividade da soja. Pesquisa Agropecuária Brasileira, Brasília, v.39, p.581-588, 2004.

CECCON, G.; STAUT, L.A.; SAGRILO, E.; MACHADO, L.A.Z.; NUNES, D.P.; ALVES, V.B. Legumes and forage species sole or intercropped with corn in soybean-corn succession in Midwestern Brazil. Revista Brasileira de Ciência do Solo, Viçosa, v.37, n. 1, p.204-212, 2013.

COMPANHIA NACIONAL DO ABASTECIMENTO (CONAB). Grãos safra 2012/2013: Décimo segundo levantamento. 2013. Disponível em: <http://www.conab.gov.br/OlalaCMS/ uploads/arquivos/13_09_10_16_05_53_boletim_portugues_ setembro_2013.pdf>. Acesso em: 19 set. 2013.

DAN, H.A.; BARROSO, A.L.L.; DAN, L.G.M.; PROCÓPIO, S.O.; OLIVEIRA JR., R.S.; CONSTANTIN, J.; FELDKIRCHER, C. Supressão imposta pelo mesotrione a Brachiaria brizantha em sistema de integração lavourapecuária. Planta Daninha, Viçosa, v.29, n.4, p.861-867, 2011.

DAN, H.A.; OLIVEIRA JR., R.S.; CONSTANTIN, J.; DAN, L.G.M.; BRAZ, G.B.P.; BALBINOT, E.; SOUSA, F.G.; REIS, R.H.P. Controle de plantas daninhas em sistemas de cultivo consorciados. Revista Brasileira de Herbicidas, Londrina, v. 1 1, n. 1, p. 108-1 18, 2012.

FRANCHINI, J.C.; SARAIVA, O.F.; DEBIASI, H.; GONÇALVES, S.L. Contribuição de sistemas de manejo do solo para a produção sustentável da soja. Londrina: Embrapa Soja, 2008. 12p. (Circular técnica, 58).

FREITAS, F.C.L.; FERREIRA, L.R.; FERREIRA, L.A.; SANTOS, M.V.; AGNES, E.L.; CARDOSO, A.A.; JAKELAITIS, A. Formação de pastagem via consórcio de Brachiaria brizantha com o milho para silagem no sistema plantio direto. Planta Daninha, Viçosa, v.23, p.49-58, 2005.

FREITAS, F.C.L.; SANTOS, M.V.; MACHADO, A.F.L.; FERREIRA, L.R.; FREITAS, M.A.M.; SILVA, M.G.O. Comportamento de cultivares de milho no consórcio com Brachiaria brizantha na presença e ausência de Foramsulfuron + IodosulfuronMethyl para o manejo da forrageira. Planta Daninha, Viçosa, v.26, p.215-221, 2008

JAKELAITIS, A.; SILVA, A.A.; FERREIRA, L.R.; SILVA, A.F.; FREITAS, F.C.L. Manejo de plantas daninhas no consórcio de milho com capim-braquiária (Brachiaria decumbens). Planta Daninha, v.22, n.4, p.553-560, 2004.

JAKELAITIS, A.; SILVA, A.A.; FERREIRA, L.R.; SILVA, A.F.; PEREIRA, J.L.; VIANA, R.G. Efeito de herbicidas no consórcio de milho com Brachiaria brizantha. Planta Daninha, Viçosa, v.23, p.69-78, 2005a.

JAKELAITIS, A.; SILVA, A.F.; SILVA, A.A.; FERREIRA, L.R.; FREITAS, F.C.L.; VIVIAN, R. Influência de herbicidas e de sistemas de semeadura de Brachiaria brizantha consorciada com milho. Planta Daninha, Viçosa, v.23, n. 1, p.59-67, 2005b.

KARAM, D.; SILVA, J.A.A.; PEREIRA FILHO, I.A.; MAGALHÃES, P.C. Características do herbicida tembotrione na cultura do milho. Sete Lagoas: Embrapa Milho e Sorgo, 2009. 6p. (Circular técnica, 129).

VILELA, L.; MARTHA JR., G.B.; MACEDO, M.C.M.; MARCHÃO, R.L.; GUIMARÃES JR., R.; PULROLNIK, K.; MACIEL, G.A. Sistemas de Integração Lavoura-Pecuária na região do Cerrado. Pesquisa Agropecuária Brasileira, Brasília, v.46, n.10, p. $1127-1138,2011$. 